\title{
Does pasture plant diversity influence abundance and diversity of lacewings and Hymenopteran parasitoids?
}

\author{
Philippa J. Gerard*, Derrick J. Wilson and Anastazia L. Docherty \\ AgResearch, Ruakura Research Centre, Private Bag 3123, Hamilton, New Zealand \\ ${ }^{*}$ Corresponding author: pip.gerard@agresearch.co.nz
}

\begin{abstract}
The lack of plant biodiversity in New Zealand pastoral ecosystems may limit the abundance and diversity of generalist parasitoids and predators, predisposing these ecosystems to pest outbreaks. To test this hypothesis, patches of turf were established in existing pasture during spring 2016. Four treatments of increasing plant complexity were established, commencing with ryegrass alone, and increasing exponentially up to eight species of forage plant per patch. In the summer of 2017, insects were collected from the patches and control plots using suction to assess whether or not plant diversity had influenced the abundance and diversity of lacewings and parasitic Hymenoptera aggregating in the patches. Plant species richness had no impact on lacewing abundance but fewer parasitic Hymenoptera were recovered from the ryegrass-only plots compared with more species rich plots. Also, a wider range of parasitoid families were represented in the more diverse plant treatments compared with the less diverse treatments. Such diversity may have beneficial impacts on the stability of pasture ecosystem and the risk of pest outbreaks.
\end{abstract}

Keywords Biodiversity, pasture, Micromus tasmaniae, parasitoid

\section{INTRODUCTION}

Most lowland pastures in New Zealand are based on perennial ryegrass (Lolium perenne L.) and white clover (Trifolium repens L.). Ecological theory suggests that such simple agroecosystems are inherently unstable, and vulnerable to invasions (Kennedy et al. 2002) and pest outbreaks (Murdoch 1975). This is supported by long-term international studies which have shown that grassland plant species richness strongly affects the colonisation of new species into the community (Weisser et al. 2017) and that reductions in plant diversity shift arthropod communities from being predator/parasitoiddominated to herbivore-dominated (Haddad et al. 2009).

Poor pasture persistence is ranked as one of the most important factors currently limiting farm economic performance in New Zealand, with drought and insect pests implicated as the main drivers (Tozer et al. 2016). However, there is limited research on terrestrial biodiversity in production landscapes and how it may impact on agroecosystem communities and resilience (Moller et al. 2008). Indeed, the lack of plant diversity in pastures is postulated to underlie the loss of efficacy of Microctonus hyperodae Loan (Hymenoptera: Braconidae); the biocontrol agent introduced to control the Argentine stem weevil (Listronotus bonariensis (Kuschel) (Coleoptera: Curculionidae) (Goldson et al. 2014; Tomasetto et al. 2017). The potential benefits of increasing pasture plant diversity on invertebrate community composition were demonstrated in a study by Tozer et al. (2016) across five regions in New Zealand. They found that although the inclusion of the forage herbs chicory (Cichorium intybus L.) or plantain (Plantago lanceolata L.) in a grass-legume pasture had no impact on herbivorous invertebrates, it resulted in a $65 \%$

New Zealand Plant Protection 71: 207-213 (2018)

https://doi.org/10.30843/nzpp.2018.71.185 
increase in predator and parasitoid abundance.

In spring 2016, an AgResearch field trial commenced to test a novel technique of introducing patches of varying plant diversity into a range of typical ryegrass/white clover pastures in Waikato, Canterbury and Otago. This technique involved freezing turves to remove resident macroinvertebrates, establishing the desired plant populations, returning the turves to the source pasture to allow invertebrates to colonise the empty niches in the turves, then removing turves at intervals and heat extracting the invertebrates using a Tullgren/Berlese funnel system. The perceived advantages of this approach were that soil structure was maintained, patch treatments could be established more reliably and with less labour than transplanting seedlings directly in the field, and there was certainty that the exact turves were recovered at time of sampling. If this patch technique proves successful, studies could be initiated into how different forage plant combinations impact on the linkages between above- and below-ground food webs within the wider pasture ecosystem. This paper reports on a supplementary study at the Waikato site only, aimed at assessing the effect of patch plant species richness on the types and numbers of highly mobile natural enemies, in particular parasitic Hymenoptera. The study was based on suction samples, and collected species generally lost during removal and heat extraction of turves. The final field assessments of the main study were completed in 2018 and at time of writing, the results were yet to be analysed.

\section{MATERIALS AND METHODS}

One hundred and twenty $18 \times 18 \mathrm{~cm}$ turves (12 $\mathrm{cm}$ deep) were dug at $1 \mathrm{~m}^{2}$ intervals from a paddock on the Ruakura Research Farm in November 2016, placed individually in $30 \times 30 \mathrm{~cm}$ polypropylene mesh onion bags, which were then folded over the turf surface. The bagged turves were placed upside down in black polyethylene planter bags and frozen at $-20^{\circ} \mathrm{C}$ for 7 days to kill any macro invertebrates present in the soil. Once the turves had thawed, the treatments were sown on the exposed soil surface through the onion bag mesh. Each turf surface was divided into sixteen equal sections in a $4 \times 4$ grid pattern. A single seed was sown in each section to form a sampling unit of a patch of 16 evenly spaced plants on a bagged $12-\mathrm{cm}$-deep turf. There were four treatments (A, B, C, and D) of increasing patch diversity ranging from ryegrass alone (16 ryegrass plants/patch) to eight different pasture plants (two plants of each/patch) (Table 1). The treatment combinations were based on plant combinations likely to be used by farmers. There were originally 30 replicates of each treatment but as half had already been destructively

Table 1 Pasture species and cultivars used in four treatments (A, B, C and D) of increasing patch diversity.

\begin{tabular}{llllll}
\hline Plant species & Cultivar & A & B & C & D \\
\hline Diploid perennial ryegrass Lolium perenne & One 50 AR11 & + & + & + & + \\
White clover Trifolium repens & Bounty & & + & + & + \\
Red clover Trifolium pratense L. & Relish & & & + & + \\
Timothy grass Phleum pratense L. & Summergraze & & & + & + \\
Plantain Plantago lanceolata & Tonic & & & & \\
Chicory Cichorium intybus & Puna 2 & & & & + \\
Tetraploid perennial ryegrass L. perenne & Base AR1 & & & & \\
Cocksfoot Dactylis glomerata L. & Tekapo & & & & + \\
Total cultivars & & & & & + \\
\hline
\end{tabular}

${ }^{1} \mathrm{AR} 1$ is a strain of the fungal endophyte Epichloë festucae var. lolii. 
harvested in for assessments in the main trial, only 15 remained at the time of this investigation.

The plants were allowed to grow for approximately 6 weeks before the planter bags were removed and the turves, still encased in onions bags, were replaced in the paddock in a 8 $\times 15 \mathrm{~m}$ grid pattern on 16 January 2017 . The patch layout was a randomised block design. The turves were not returned to their original locations as the holes had to be filled in for stock safety and the pasture in the vicinity of the former holes had not recovered fully. The trial site, which was in an old ryegrass/white clover pasture, was grazed by sheep. However, due to intense selective grazing of the broadleaf species, metal cages had to be placed over each patch partway through the trial and the patches mown to grazing height after stock had been removed.

On 20 December 2017, a Vortis ${ }^{\circledR}$ arthropod suction sampler was held over the centre of each of the 60 patches for 5 seconds and the samples collected put into individually labelled $60 \mathrm{~mL}$ specimen containers with $30 \mathrm{~mL} 70 \%$ ethanol. The samples were then assessed in the laboratory by tipping the vial contents into a glass Petri dish with a grid base and counting then removing lacewings (Neuroptera: Hemerobiidae) and parasitic Hymenoptera. These were placed in labelled vials containing 70\% ethanol and later the parasitoids were sorted into Superfamilies, then Families. The Chalcidoidea were further sorted into morphospecies based on antennae characteristics, wing venation and body shape, and the number of morphospecies in each sample recorded.

The turves were removed from the pasture on 15 January 2018 and patches assessed for the presence or absence of the sown plants and major weed species. The diploid and tetraploid ryegrasses were counted as a single species.

The insect suction and plant data from patches were analysed using ANOVA with number of plant species present (including major weed species) and whether an individual sown species was present tested as covariates.

\section{RESULTS}

A year after sowing, it was apparent that volunteer species present in the pasture had established in all patches. The most common were white clover, wild plantain and members of the dandelion group of weeds, in particular hawksbeard (Crepis capillaris L.) and hawkbit (Leontodon taraxacoides Mérat). Furthermore, chicory, cocksfoot and especially Timothy grass did not persist in most Treatment D replicates, which were dominated by ryegrass. Nevertheless, representatives of the sown plant species were found in patches of the appropriate treatments and the treatments had a significant range in plant species richness (Table 2).

Treatment alone did not have a significant effect on parasitoid abundance $(\mathrm{P}=0.077)$ but when adjusted for white clover presence, the treatment effects became statistically significant (Table 2). No other plant species significantly influenced parasitoid abundance, with red clover being the closest $(\mathrm{P}=0.063)$.

Representatives of five parasitic Hymenopteran superfamilies were found, with Chalcidoidea (families Chalcididae and Mymaridae), the largest superfamily in the Order, being by far the most numerous, followed by Prototrupoidea (Diapriidae) (Table 3). Other superfamilies represented were Platygastroidea (Platygastridae and Scelionidae), Ceraphronoidea (Megasilidae) and Ichneumonoidea (Braconidae). Only two Braconids were found and neither were the Microctonus species introduced to control Argentine stem weevil and clover root weevil Sitona obsoletus (Gmelin), pest species commonly found on the research farm. There was a strong effect of treatment on diversity of parasitoid families present, in particular when the number of plant species present was used as a covariate (Table 2), with Treatments A and B having fewer families compared with Treatments C and D.

The mean numbers of parasitoid adults in the families most commonly found in patches are shown in Table 3. Only two families showed a significant response to plant diversity treatment, with small wingless Scelionids found in Treatment $\mathrm{D}$ and most Chalcids found 
Table 2 Mean number/patch of plant species, lacewing adults, Hymenopteran parasitoids and parasitoid Families recovered from patches sown with increasing diversity of pasture plant species.

\begin{tabular}{lllll}
\hline Patch code & Plant species & Lacewings & Parasitoids $^{1}$ & Parasitoid Families $^{2}$ \\
\hline $\mathrm{A}$ & $3.53 \mathrm{a}^{3}$ & $0.60 \mathrm{a}$ & $3.29 \mathrm{a}$ & $1.17 \mathrm{a}$ \\
$\mathrm{B}$ & $3.53 \mathrm{a}$ & $0.87 \mathrm{a}$ & $5.18 \mathrm{ab}$ & $0.97 \mathrm{a}$ \\
$\mathrm{C}$ & $4.27 \mathrm{~b}$ & $0.80 \mathrm{a}$ & $7.51 \mathrm{~b}$ & $1.83 \mathrm{~b}$ \\
$\mathrm{D}$ & $5.07 \mathrm{c}$ & $0.87 \mathrm{a}$ & $5.22 \mathrm{ab}$ & $1.97 \mathrm{~b}$ \\
& & & & \\
Probability & $\mathrm{P}<0.001$ & 0.84 & 0.034 & 0.005 \\
L.S.D. & 0.72 & 0.67 & 2.69 & 0.59 \\
\hline
\end{tabular}

${ }^{1}$ Patch white clover presence used as a covariate: Coefficient $=-2.5$

${ }^{2}$ Plant species number used as a covariate: Coefficient $=-0.17$

${ }^{3}$ Values within columns followed by the same letter are not significantly different according to L.S.D at $\mathrm{P}=0.05$.

Table 3 Mean number/patch of parasitoids in the four most abundant parasitic Hymenopteran Families, and number of Chalcid morphospecies, recovered from patches sown with increasing diversity of pasture plant species. Plant species were used as a covariate.

\begin{tabular}{llllll}
\hline Patch code & Megasilids & Diapriids & Scelionids & Chalcids & Chalcid morphospecies \\
\hline A & $0 \mathrm{a}$ & $0.49 \mathrm{a}$ & $0.06 \mathrm{a}$ & $2.95 \mathrm{a}$ & $2.00 \mathrm{a}$ \\
$\mathrm{B}$ & $0.04 \mathrm{a}$ & $0.09 \mathrm{a}$ & $0 \mathrm{a}$ & $4.62 \mathrm{ab}$ & $3.07 \mathrm{ab}$ \\
C & $0.27 \mathrm{a}$ & $0.61 \mathrm{a}$ & $0 \mathrm{a}$ & $6.23 \mathrm{~b}$ & $3.85 \mathrm{~b}$ \\
D & $0.05 \mathrm{a}$ & $0.74 \mathrm{a}$ & $0.35 \mathrm{~b}$ & $4.26 \mathrm{ab}$ & $3.42 \mathrm{~b}$ \\
& & & & & \\
Probability & 0.075 & 0.229 & 0.041 & 0.048 & 0.067 \\
L.S.D. & 0.25 & 0.63 & 0.264 & 2.41 & 1.42 \\
\hline
\end{tabular}

in Treatment C. The maximum number of Chalcididae morphospecies found in a patch sample was eight and a third of Treatment C samples had at least five morphospecies.

The only species of lacewing present was the Tasmanian lacewing Micromus tasmaniae (Walker) (Neuroptera: Hemerobiidae). It was relatively evenly distributed across the four treatments, and abundance was not influenced by plant species richness or individual sown species present (Table 2).

\section{DISCUSSION}

The objective of this experiment was to test a technique for introducing patches of varying plant diversity into typical New Zealand pastures for the purposes of studying invertebrate food webs. Although the data presented is just a single snapshot in time at a single site, the outcomes have been positive in that increased plant species richness did result in increased abundance and variety of parasitic Hymenoptera.

The turf technique was effective in creating small patches of varying plant species richness in established pasture for at least a year. While weeds were common in the patches, their impact could be reduced in future experiments by allowing time for seed-bank weed- seed germination and seedling removal before sowing the treatments. In retrospect, greater differences between treatments may have been achieved by selecting plants for functional differences 
rather than 'farmer use'. For example, it may have been better to introduce the above- and belowground architectural complexity associated with plantain and chicory in Treatment C, rather than Treatment D. Furthermore, having a second ryegrass in Treatment $\mathrm{D}$ was likely to have had a negative effect on invertebrate abundance. Both ryegrasses contained a strain of fungal endophyte that provides protection against attack by invertebrate herbivores and enables them to persist in pasture longer than forage grasses not protected by endophytes. This can in turn impact on parasitoid abundance (Müller et al. 2007).

Hymenopteran parasitoid adult abundance and Family species richness were influenced by the plant diversity treatments. This result in pasture aligns with previous research from two long-term grassland biodiversity experiments, although the Jena Experiment in Germany (Petermann et al. 2010) and the Cedar Creek experiment in the USA (Tilman 1996). However, only the Jena Experiment had plant species in common (Timothy grass, cocksfoot and red and white clover). The Cedar Creek experiment showed herbivore and predator/parasitoid species richness were strongly positively related to plant species richness within plots (Haddad et al. 2009). Furthermore, primary parasitoid levels were directly affected by changes in plant species diversity in the Jena Experiment with highest densities and species richness occurring at intermediate plant species richness. However, hyperparasitoids declined linearly with plant species diversity owing to sparser resources (Petermann et al. 2010). Both the Cedar Creek (Tilman 1996) and Jena (Petermann et al. 2010) experiments included forbs that are known good nectar sources for Hymenopteran parasitoids. At the latter site, an investigation by Nitschke et al. (2017) of a tri-trophic system composed of Centaurea jacea (brown knapweed), tephritid flies and their hymenopteran parasitoids, showed that parasitoid abundance increased with surrounding plant diversity. However, the presence of legumes decreased parasitism rates, which the authors deduced was because parasitoids could not access legume nectar. At time of sampling in the current study, plantain and members of the dandelion family were the main plants flowering in both the patches and surrounding pastures. Therefore, given the small size of the patches, it is unlikely nectar sources affected parasitoid aggregation on patches in this study.

Of the plant species tested, only white clover influenced parasitoid abundance, probably because it is host to a range of invertebrate herbivores common in New Zealand pastures. The results suggested red clover may play a role also and the presence of both white and red clover may underlie why Treatment $\mathrm{C}$ attracted most parasitoids. The main study should provide published data on this supposition. It is highly likely the presence of Scelionids in Treatment $\mathrm{D}$ is due to the more complex plant architecture provided by red clover, plantain and chicory in these patches relative to surrounding pasture. These parasitoids all belonged to tribe Baeini, which are endoparasitoids of spider eggs. Webbuilding spider abundance is known to increase with increased grassland spatial heterogeneity (Gómez et al. 2016).

In contrast, Tasmanian lacewing adult abundance was neither affected by plant species richness nor the presence of members of the dandelion group, the main plants flowering at time of sampling. This lacewing is one of the most common generalist predators in New Zealand cropping systems (Walker et al. 2011), but while they consume a range of invertebrates, they show a strong aggregative numerical response to aphid density (Leathwick 1989). In addition, Jacometti et al. (2010) showed that prey density and the availability of nectar resources can differentially affect Tasmanian lacewing abundance.

In summary, while the results reported are from just one sampling date, they show that small diverse patches within pasture do have a significant impact on the abundance and species richness of the parasitoids that aggregate on them. Given the positive benefits of the inclusion of chicory and/or plantain in New Zealand pastures on predator and parasitoid abundance (Tozer et al. 2016), more detailed study is warranted 
to quantify how pasture plant diversity impacts on pasture ecosystem stability and pest outbreak risk.

\section{ACKNOWLEDGEMENTS}

The authors wish to thank Scott Hardwick and Colin Ferguson for their input into the patch diversity trial and comments on this manuscript. We thank Peter Johnstone for the statistical analyses and Tim Hale, the Ruakura Farm manager, for use of the site.

This paper is based on work done by Anastazia Docherty as part of her Waikato University B. Sci. Tech. summer studentship placement. The main trial was supported through funding from AgResearch Staff Technology Award.

\section{REFERENCES}

Goldson SL, Tomasetto F, Popay AJ 2014. Biological control against invasive species in simplified ecosystems: Its triumphs and emerging threats. Current Opinion in Insect Science 5: 50-56.

Gómez JE, Lohmiller J, Joern A 2016. Importance of vegetation structure to the assembly of an aerial web-building spider community in North American open grassland. Journal of Arachnology 44: 28-35.

Haddad NM, Crutsinger GM, Gross K, Haarstad J, Knops JMH, Tilman D 2009. Plant species loss decreases arthropod diversity and shifts trophic structure. Ecology Letters 12: 10291039.

Jacometti M, Jørgensen N, Wratten S 2010. Enhancing biological control by an omnivorous lacewing: Floral resources reduce aphid numbers at low aphid densities. Biological Control 55: 159-165.

Kennedy TA, Naeem S, Howe KM, Knops JMH, Tilman D, Reich P 2002. Biodiversity as a barrier to ecological invasion. Nature 417: 636-638.

Leathwick DM 1989. Applied Ecology of the Tasman Lacewing Micromus tasmaniae Walker (Neuroptera: Hemerobiidae). Ph.D. thesis, Lincoln University, Canterbury. 129 p. Moller H, MacLeod CJ, Haggerty J, Rosin C,
Blackwell G, Perley C, Meadows S, Weller F, Gradwohl M 2008. Intensification of New Zealand agriculture: Implications for biodiversity. New Zealand Journal of Agricultural Research 51: 253-263.

Müller CB, Härri SA, Boreux V, Krauss J 2007. Grass cultivar diversity and endophyte infection affect abundance of herbivores and their natural enemies. Proceedings of the 6th International Symposium on Fungal Endophytes of Grasses: 321-324.

Murdoch WW 1975. Diversity, complexity, stability and pest control. Journal of Applied Ecology 12: 795-806.

Nitschke N, Allan E, Zwölfer H, Wagner L, Creutzburg S, Baur H, Schmidt S, Weisser WW 2017. Plant diversity has contrasting effects on herbivore and parasitoid abundance in Centaurea jacea flower heads. Ecology and Evolution 7: 9319-9332.

Petermann JS, Müller CB, Weigelt A, Weisser WW, Schmid B 2010. Effect of plant species loss on aphid-parasitoid communities. Journal of Animal Ecology 79: 709-720.

Tilman D 1996. Biodiversity: population versus ecosystem stability. Ecology 77: 350-363.

Tomasetto F, Tylianakis JM, Reale M, Wratten S, Goldson SL 2017. Intensified agriculture favors evolved resistance to biological control. Proceedings of the National Academy of Sciences of the United States of America 114: 3885-3890.

Tozer KN, Barker GM, Cameron CA, Wilson D, Loick N 2016. Effects of including forage herbs in grass-legume mixtures on persistence of intensively managed pastures sampled across three age categories and five regions. New Zealand Journal of Agricultural Research 59: 250-268.

Walker GP, MacDonald FH, Larsen NJ, Wallace AR 2011. Monitoring Bactericera cockerelli and associated insect populations in potatoes in South Auckland. New Zealand Plant Protection 64: 269-275.

Weisser WW, Roscher C, Meyer ST, Ebeling A, Luo G, Allan E, Beßler H, Barnard RL, Buchmann N, Buscot F, Engels C, Fischer 
C, Fischer M, Gessler A, Gleixner G, Halle $\mathrm{S}$, Hildebrandt A, Hillebrand $\mathrm{H}$, de Kroon H, Lange M, Leimer S, Le Roux X, Milcu A, Mommer L, Niklaus PA, Oelmann Y, Proulx R, Roy J, Scherber C, Scherer-Lorenzen M, Scheu S, Tscharntke T, Wachendorf M, Wagg C, Weigelt A, Wilcke W, Wirth C, Schulze ED, Schmid B, Eisenhauer N 2017. Biodiversity effects on ecosystem functioning in a 15-year grassland experiment: Patterns, mechanisms, and open questions. Basic and Applied Ecology 23: 1-73. 